\title{
The Female Fidelity in the Perspective of Ecological Feminism: Rebellious Zhu Mu and Restrained Penelope - Based on Gesar Epics and Homeric Epics
}

\author{
Daiqiong $\mathrm{Liu}^{1, \mathrm{a}}$ \\ ${ }^{1}$ English Department, Sichuan Minzu College, Kangding, Sichuan, China, 626001
}

\begin{abstract}
Keywords: Ecological Feminism; Male Chauvinism; Female Consciousness
\end{abstract}
\begin{abstract}
Ecological feminism thinks that women and nature are dominated by the idea of male power, naturally dominated by men and women are male discrimination, so there is an internal relation between the female and nature. By comparing the relationship between nature and men, it is found that both women and nature are in oppressed positions in male-dominated societies. Due to the living environment and social form and other differences, with the faithful female image, Zhu $\mathrm{Mu}$ has a hazy female consciousness and the spirit of struggle, and Penelope was deeply attacked by male thought and it tends to forbear. Whether Zhu Mu's struggle or Penelope's tolerance still cannot change their fate of the victims of Male Chauvinism. Analysis of the image of $\mathrm{Zhu} \mathrm{Mu}$ and Penelope so that we can emancipate women and solve the ecological crisis, only to completely overthrow the idea of Male Chauvinism in order to truly promote the contemporary female self-identity identity seeking, construction and recognition to achieve ecological sense of harmony among human and natural, male and female.
\end{abstract}

\section{Introduction}

Tibetan Gesar Epics and Homeric Epics (ie "Iliad" and "Odyssey") are based on the ancient Tibetan, ancient Greek history, mythology, folklore, songs and other based on the formation of two Minister of heroic epic. Gesar Epics and Homeric Epics as treasures in the folk literature library, praised Gesar and Odysseus, led by many heroes of wisdom, strength, virtue and performance, disseminated with a strong myth Color; at the same time, the two are their own national "encyclopedia", a high degree of summary of the ancestors of the production activities, customs, national spirit, religious beliefs. "In the era of hero epic, due to the development of social productive forces, man has achieved a certain victory for God, who has begun to have the same power as God, and even contend with God." [1] In other words, The different status and role of the two heroes in the epic are just in line with the tendency of mankind to gradually enjoy the dominance of nature in a way. At the same time, due to the division of labor, the decline of social and economic status, the marital form and so on led to the loss of women's discourse, in a relatively weak position, the female image was firmly confined to the traditional male supremacy of gender norms. In the ecological crisis is increasingly serious today, the ecological demands and feminist perspective combined to study the "Huo Ling war" and "Odyssey" in the image of Zhu Mu and Peyer Lopei female, as good as to break the male discourse, to promote modern people To carry out ecological humanistic reflection, and from the ecological sense to further promote the contemporary female self-subject identity seeking, construction and recognition of effective ways.

\section{The Introduction of Ecological Feminism}

As the name suggests, ecological feminism is about feminism and ecology theory. The term "Ecofeminism" was originally proposed by the French feminist Francoise D'Eaubonne in 1974. She believes that there is a certain connection between women and nature, are in the dominant position, naturally dominated by mankind, women are male discrimination, and therefore called on women to lead an ecological movement, to re-examine the relationship between mankind and nature. To this end, Karen J. Warren (Karen J. Warren) to expose the oppressive conceptual structure is the 
patriarchal slavery of women and the theoretical basis of nature, mainly including the value of the system of thinking, dualism and logic of the three categories of logic. P38 Valplumwood (Val Plumwood) from the rationalist tradition, especially on the dualism to attack. She believes that in accordance with the dualistic mode of thinking in the Western rationalist tradition, man and nature, men and women are separated, is opposed and separated, causing serious polarization. P39 to amend and adjust this relationship, we must put the liberation of women and solve the ecological crisis together as the ultimate goal; the same time, to thoroughly understand the "patriarch" ecological concept and its essence, to overthrow the patriarchal culture of nature and women's rule, In order to fundamentally alleviate and even eradicate the "natural discrimination" and "female discrimination" to achieve the human and nature, male and female ecological harmony.

\section{The Ecological Feminist Perspective of Female Images in Zhu Mu and Penelope}

Eco feminists argue that "in 'dualism', men represent 'people', 'human' and 'rational' parties, while women represent 'natural', 'animal' or 'emotional' side, and therefore, male And women, man and nature are hostile to each other. "[2] P39 Here," male "is the ecological feminist sense of" human "," female "was" natural ", and men are women and The connection of natural inner relations. Thus, the relationship between male and female is conducive to the excavation of the image of the bead and Penelope.

The Relationship among Zhu Mu, Penelope and Nature. Marx once said that man and nature are an organic whole, and man is a part of nature; there is an interaction between man and nature; nature is the foundation of human existence and development. It is a combination of "Huo Ling war" and "Odyssey" (hereinafter referred to as "Huo" and "Austrian") and the relationship between natural relations and its performance to reveal the two women and nature in the patriarchal thinking mode the status and situation.

As mentioned above, there is a close connection between nature and women, and nature and women are shining with the common maternal beauty in the breeding of life. First of all, the beauty of nature and female beauty is harmonious and unified. And placed in such a beautiful scenery in the first beauty of the country, Gesar's wife, namely Zhu Mu "skin like white Kam satin / flesh moisturizing such as Hongjuan / flexible bright eagle eye / eyebrows crescent bend and bend / ... / Smile is worth a hundred sheep / tongue from the "A" shape / although there are hundreds of sheep are hard to change / she is the world's top girl / children on the earth decorations / Ling country daughter in a elite / She is one. "[3] P10-11 the connection between the bead and the nature is also reflected in her relationship with the three samurai. "Long neck bird bird white crane, long wings a stretch to the empty, show legs point to earth, long beak pecking beauty charm." [4] This song popular in the Tibetan area is not only show the crane crane Noble praise of the posture, but also reflects the beads between the animals and animals know each other and the relationship between nature and the feelings of solidarity.

In Odyssey the description the natural scenery is not much, but vaguely able to see its soil "fertile". Odysseus returned to Ithaca and his father met, he recalled: "give me thirteen pear trees / ten apple trees and forty fig trees together / you also promised me fifty Ridge grapes / ripening at different times / each successive result / whenever the Zeus empty account of the season from the sky, out of the branches down. "[5] on the appearance of Penelope narrative is not much, with more words "Fullness", indicating that the abundance of body in the ancient Greek culture is a symbol of health and fecundity, is the beauty of women and maternal beauty of the symbol, and it with the natural "fertile" corresponds to that women and nature have a similarity. In addition, Peggy Lopez daily control is mainly reflected in the manual textile, agriculture and animal husbandry, and these in turn she and nature closely linked.

The Relationship among Zhu Mu, Penelope and Men. In the matriarchal clan society, women have a high social status, but with the development of mankind, the emergence of social production and division of labor so that human beings on the natural, male women have a dominant power, making ecological damage, women are oppressed. "The maternity system was overthrown, but the failure of women in the history of the world, the husband at home also mastered the authority, and 
his wife was belittle, enslaved, into her husband lust slaves, into a simple tool for children. "[6] Engels pointed out sharply led to Zhu Mu and Penelope women's fate and character characteristics of the most profound social reasons. In the male ideology, men are at the highest level of dominance, the female object, that the women, the natural slavery is reasonable.

First of all, Zhu Mu in the male culture under the repression, showing a woman's consciousness, launched a struggle against patriarchy. In the marriage, for the purpose of political and economic marriage, Zhu Mu parents make her promised to the big food of the prince, but Zhu Mu not from the courage to refuse this marriage, and choose to pursue true love, At that time the impoverished Gesar (known as the horse before the king said) through thick and thin. In the marriage life, Engels once said that polygamy is the product of slavery, only the figure of the characters can be done. Zhu Mu's marriage form is polygamous(Gesar has the thirteen wives in total), so she cannot get from the husband's feelings of reciprocal feedback. Zhu $\mathrm{Mu}$ at this stage of the female consciousness reflected in the fight with other concubines, but in the idea of no real awakening, so her resistance is only to bite the stone fills. In the Gesar expedition to save Mesa, Zhu Mu alone keep empty for three years, looking forward to her husband, but to wait for a catastrophe. Ridge of the northeast of the Hall of the white king of the king suddenly died, want to marry Zhu Mu for the Princess, so the war, ordered the Simba Mau Ze "all God destroyed all the light / all dome all killed light / all the temple All burning light / all things all seize the light! "[3] P12 This is to some extent, charcoal creatures, causing a certain degree of destruction of nature. Later, Gesar in the peace after the Hall, he brutally executed Zhu $\mathrm{Mu}$ and white son Wang birth son. For whatever reason, Gesar as the highest symbol of male power, deprived of Zhu Mu as the mother's duty and rights, to her body and mind caused a huge trauma. As he was in the king before, "to the Sai Yu Shan, killing the monkey three brothers, wearing sheepskin do ugly hat, to the Explorer's bullpen, kill the lucky demon calves, Cowhide leather to the tiger leather, to Chao Tong's tranquil, stole the white nose ghost horse, put on the horse with the horse to do the red waist horse boots. "[7] his behavior to harm the animals, destroyed the ecology balance. Of course, we should use a daze to look at Gesar, after all, look at his life, he is more committed to the promotion of nature, to seek harmony between man and nature.

Second, Zhu Mu in economic life attached to men, cannot really independent. In the era of Gesar, the social division of labor has been relatively clear, men and more engaged in animal husbandry and farming can get paid labor, and women are mainly engaged in water, wine, textiles, milking and boiled tea and other unpaid housework. "Yang tea to be like a swan into the community of the sea / Yang a scoop and a scoop / cow dung like a hero, should pile up burning / wood like a hero, need to turn the burning / cypress like a god of war, need to mix burning / cat thorn Monsters, need to crush the burning. "[8] that Zhu Mu personally involved in daily fire, boiled tea, wine, horse and other daily labor to go, but because of its labor is considered to be unable to obtain paid domestic work, So the economic status is low, still subject to men.

As a result of long-term patriarchal ideology, Penelope has a feminist tendency, feminine consciousness is weak, is the patriarch of the victims and accomplices. Its marriage is nominally monogamous, and she is actually deliberately shaped out by the world respected and admired the ancient Greek women's moral model only. Odysseus said to Peggy Lopez when she was away from home. "I'm sorry to go to the gods and let me return and / or kill Troy, and now entrust things with you / I leave you at home. Such as now, even more than I am at home / but when you see the child grow up to give birth mustache must / you can leave this home, choose to love the marriage. "[9] This shows Odysseus identity" Outside the female within the "division of the model of men and women, can not be paid to the housework assigned to Penelope, so that the economy attached to men. Odysseus also regarded the husband and wife, kind and gentle and there are also other characters as an important label of female beauty, Penelope gender roles and maternal characteristics of stylized, standardized, and reputation to promote and commend. Therefore, in the face of many suitors, Penelope was still subject to the control and discipline of male discourse cannot be righteous to refuse, indecisive. Odysseus on the way back, he not only get the God of wind, Athena goddess and other help, but also with Zeus, Poseidon and other gods confrontation, the actual embodiment of the binary opposition and unity of nature, this is Because with the human 
process and development, mankind began to realize that they have the ability to change and influence the natural, and ignited the control of nature, the desire to control nature.

\section{The Female Image of Zhu Mu and Penelope Embodied in the Modern Ecological Humanities Reflection}

After combing the discovery, Zhu Mu, Penelope and nature are inextricably linked, their female beauty and natural beauty complement each other and their hard work also through intimate contact with nature to be reflected at the same time from them also can see the natural maternal color. At the same time, we must also realize that in the male-dominated society, Zhu $\mathrm{Mu}$, Penelope and nature are the object of domination and domination. As the ancient Tibetan and ancient Greek women's spirit and fate of the prototype, Zhu Mu and Penelope were ancient Tibetan and ancient Greek society, thousands of female images of the epitome of the body reflected in the background and national flavor. It should be pointed out that the pearl at the end of the Tibetan matriarchal clan transition to the patrilineal clan stage, women are still the main force of daily production and life, and Peyer Lopei where the ancient Greek society has entered the patrilineal clan and the next stage of transition, Men play an increasingly important role in production and life, and the establishment of this patriarch makes women's social status decline. In contrast, Zhu $\mathrm{Mu}$ is more resistant to the struggle against male power and she tried to oppose polygamy, against war, against patriarchy, but always cannot break through the barriers of social roles. And Penelope in the process of struggle with the male power is more to take the way of Tolerance, revealing her succumb to patriarchal ideology, subject to her husband, seeking people, lack of subjective consciousness, the lack of protest spirit and courage, which shows that Ancient Greek gender status is seriously imbalanced. Thus, the bead is fresh, publicity, and Penelope is depressed, forbearance. In the male form of the supremacy of the deformity of the social form, whether it is the struggle of the beads or Toledo Penelope, they are male accessories and property, under this system of male rights, and women interdependent nature Faced with the same situation. In the 21st century, women's discrimination and ecological crisis are still common problems faced by mankind. Only by breaking the rule of male-dominated discourse can women find the real liberation of body and mind in order to realize the seeking, construction and recognition of female self-subject identity between women and men, the harmonious relationship between man and nature.

\section{Acknowledgements}

Fund Project: 2017 Sichuan Provincial Department of Education Humanities and Social Sciences General project "The Comparative Study of Tibetan "Gesar Epic" and Greek "Homeric Epic" Based on the Perspective of Ecological Anthropology "(No. 17SB0360)

\section{References}

[1] Zhu Yichu, Li Zixian. Introduction to minority folk literature[M]. Kunming: Yunnan People's Publishing House, 1983: 152.

[2] Xiao Wei. Ecological feminism and its ethical culture[J]. Foreign Women's Studies, 2000 (4): 36-41.

[3] Chinese Folk Literature and Art Research Association of Qinghai Branch. Huo Ling war (on) [M]. Xining: Qinghai People Publishing House, 1984: 10-11.

[4] Dora. Zhu Mu and the crane and "Gesar" in the original ecological culture[J]. China Tibet, 28-29.

[5] (Ancient Greece) Homer. Odyssey[M]. Chen Zhongmei Annotation. Nanjing: Translation Lin Publishing House, 2003: 793. 
[6] Engels. Family, private ownership and the origin of the country [A]. Marx, Engels anthology of Volume[M]. Beijing: People Publishing House, 1972: 52.

[7] Gesar King Biography. Huaring birth of the Ministry[M]. Wang Yiyuan translation. Lanzhou: Gansu People Publishing House, 1985: 42.

[8] Gesar King Biography (Guide chapter chapter) [M]. Wang Yiyuan, Huaji translation. Lanzhou: Gansu People's Publishing House, 1981: 49.

[9] (Ancient Greece) Homer. Homer 's Epic Odyssey [M]. Wang Huansheng Biography. Beijing: People's Literature Publishing House, 2003: 343. 